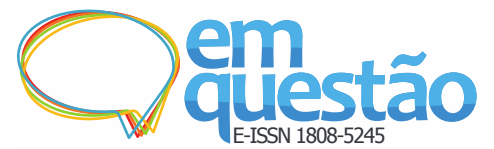

\section{Eros e a Ciência da Informação}

\author{
Solange Puntel Mostafa \\ Doutora; Universidade de São Paulo, São Paulo, SP, Brasil; \\ smostafa@terra.com.br \\ Igor Soares Amorim \\ Doutorando; Universidade Federal de Santa Catarina, Florianópolis, SC, Brasil; \\ igao.sa@gmail.com \\ Deise Maria Antonio Sabbag \\ Doutora; Universidade de São Paulo, São Paulo, SP, Brasil; \\ deisesabbag@usp.br
}

\begin{abstract}
Resumo: Experimentação sobre o deslizamento de planos entre filosofia, Ciência da Informação e Artes por meio da trilogia da incomunicabilidade formada pelos filmes dirigidos por Michelangelo Antonioni, com o objetivo de delinear e experimentar maneiras de indexar fora dos quadros do estruturalismo da Ciência da Informação. Faz-se uso do conceito filosófico de Linguagem Documentária Menor, ao apresentar novos termos para a indexação dos filmes mencionados, baseados na filosofia do cinema de Gilles Deleuze, especificando o estruturalismo da Ciência da Informação.
\end{abstract}

Palavras-chave: Linguagem documentária. Indexação. Representação descritiva. Gilles Deleuze. Michelangelo Antonioni.

\section{Introdução}

A ciência aponta para o futuro com a leveza necessária a se desprender das forças gravitacionais. A ciência levou o homem à lua e, mesmo quando erra, volta e se refaz, se corrige. Contudo, a ciência, sempre articulada com o futuro, tem seu contraponto nos sentimentos e na moral, herança advinda do tempo de Homero, da qual ainda não nos desvencilhamos. Orgulhosa herança que não admite o erro. Onde se chega com esses caducos sentimentos? Chega-se à piedade recíproca (LA NOTTE, 1961). Os personagens desse cineasta, cuja 


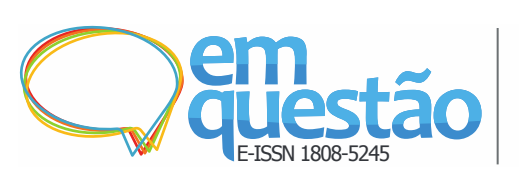

trilogia fílmica iremos analisar neste artigo, encontram-se nessa condição, quando já estão nos limites da doença de Eros, com medo da desconhecida moral. A doença de Eros, esse desequilíbrio ambientado no tempo, passado homérico, futuro técnico.

Eros, o mais belo entre os imortais, deus da união amorosa, com poder de seduzir homens e outros deuses, tem no Caos seu oponente que traz o princípio da cissura, da qual nasce a vida terrestre. Eros e Caos sempre compreendidos juntos no seio da Terra. Eros possibilita a organização da vida e do intelecto no Cosmo, e o Caos reabre as forças produtivas (HESÍODO, 1995).

O aspecto doentio que Eros imprimi nos seres é inerente para Hesíodo (1995), contudo, não nos colocamos em favor de marginalizar Eros, mas de estabelecer outros relacionamentos possíveis. Trazer mais de Eros à Ciência da Informação, por meio do deslizamento de planos entre filosofia, arte e ciência, como nos ensina Deleuze e Guattari (2010). Nosso interesse neste deslizamento é chegar aos processos de indexação da informação fílmica.

Neste sentido, o objetivo desse artigo é analisar a indexação da trilogia fílmica da incomunicabilidade do cineasta Michelangelo Antonioni, composta pelos fimes L'avventura (1960), La notte (1961) e L'eclisse (1962) que trata sobre o tema da alienação. Além disso, pretende-se observar se essa representação documental contempla o conceito de imagem-tempo de Deleuze. A análise da indexação da trilogia de Antonioni foi realizada tendo como percurso metodológico o método comparativo, sendo definido como estudo descritivo com procedimentos técnicos teórico-bibliográficos. Para tanto, utilizamos o documento normativo da International Federation of Film Archives, FIAF (FÉDÉRATION INTERNATIONALE DES ARCHIVES DU FILM, 2012), para descrição de filmes, e as proposições metodológicas de descrição fílmica do modelo de Cordeiro e Amâncio (2005), para analisar os termos de indexação da trilogia da incomunicabilidade no Internet Movie Database (c2017).

Refletir sobre a indexação da imagem em movimento, com conceitos filosóficos, buscando entender essa atividade/processo com o cinema, na 
filosofia e na ciência justifica-se pela necessidade de ampliarmos os estudos de indexação para além do enfoque do texto escrito, enriquecendo outras dimensões à análise documentaria e possibilitando novos deslizamentos à Ciência da Informação.

\section{Indexação na Ciência da Informação}

A indexação compõe uma etapa operacional da análise documentária ${ }^{1}$. Em sua face teórica, denominada Organização do Conhecimento, a análise documentária busca subsídios para o processamento formal e de conteúdo do documento.

Para Campos (1987), a “[...] indexação consiste, fundamentalmente, na captação do conteúdo informativo do documento e na tradução desse conteúdo numa linguagem que sirva de intermédio entre o usuário e o documento [...]" (CAMPOS, 1987, p. 69). A autora destaca a indexação como processo básico da recuperação de um documento, lembrando que essa é uma tarefa que envolve a sintaxe, a semântica e a pragmática. Assim, Campos (1987) afirma, já na década de 1980, a insuficiência da linguística para o avanço da teoria na área, é preciso ir além: “[...] linguística é apenas um ponto de partida para alcançar outros momentos básicos do pensar humano.” (CAMPOS, 1987, p. 71). Compactuamos com esse entendimento, mas não com as projeções de Campos que aposta na maior cientificização na correspondência entre a representação e o conteúdo do documento representado.

Entendemos esse como um problema da verdade, um problema da moral, como aborda Nietzsche (2008) em sua Genealogia da moral. Contudo, os estudos nas linguagens documentárias perseguiram e se erigiram sobre essa vontade de verdade.

Chaumier (1988) ratifica o estruturalismo enquanto base epistemológica na área, na medida em que cita termos do sistema de comunicação de Roman Jakobson, tais como "silêncio" e "ruído". O autor pontua que a indexação pode ser feita com base na linguagem natural ou artificial, sendo ela controlada por meio de um vocabulário controlado. Garcia Gutiérrez (1990) afirma que a 
linguagem documentária funda-se no estruturalismo, tendo a significação ato resultante das escolhas opcionais de combinações determinadas no uso.

Compatriota de Chaumier, o francês Gardin foi um dos primeiros a articular a Ciência da Informação à perspectiva estruturalista da linguagem, sendo ele um dos responsáveis por cunhar o termo "linguagem documentária". Gardin (1973) afirma a importância dessa relação da área com a linguística, baseando-se em três pontos:

a) é importante compreender semanticamente quais as informações fundamentais em um documento;

b) é preciso selecionar as principais noções, e arranjar estes conceitos seguindo preferencialmente um critério semântico;

c) é necessário compreender o contexto de uso desses termos (pragmaticamente).

Remetendo à Saussure, Lara (2002) cita em nota de rodapé a primazia do eixo paradigmático (referente ao arranjo vertical dos conceitos) em relação ao sintagmático (referente às definições e escolhas dos termos a serem usados). Essa base teórica, estruturalista, ainda é muito presente, até mesmo, na compreensão dos conceitos que fundamentam a área, como observamos na noção de registro de informação. Segundo Ortega e Lara (2010, p. 15):

A noção de estrutura é explicada pelas relações entre seus elementos. Ela implica articulação, internamente e no âmbito do sistema, a qual permite a identificação de características comuns entre os elementos que a compõem. O registro de informação é, portanto, uma estrutura, pois é composto por forma (campos) e conteúdo (preenchimento dos campos) que devem estar articulados.

Entendemos que a perspectiva estruturalista presente nas linguagens documentárias não são suficientes para dar conta da indexação dos documentos fílmicos. Afinal, um filme não se restringe a comunicar uma mensagem. Eles nos tocam, nos emocionam e nos fazem pensar. A maior parte dos estudos sobre indexação foi, até hoje, desenvolvida com enfoque no texto escrito. Isso motiva a consolidação relativamente tranquila das concepções estruturalistas na área. A 
imagem em movimento aumenta a complexidade com a qual os cientistas da informação precisam lidar, visto que agrega outras dimensões à análise documentária.

Com relação à imagem em movimento, Cordeiro e Amâncio (2005) buscam aportes na teoria do cinema e desenvolvem categorias ${ }^{2}$ para a indexação de filmes: gênero; registro temporal da trama; gancho temporal; referência histórica; temas representados; estrutura narrativa; natureza da representação; sequências relevantes; aproximações temáticas da(s) sequência(s) escolhida(s); sinopse; instrumentos documentais; complementações; informações extrafílmicas; e observações.

Entendemos que a análise da trilogia da incomunicabilidade do cineasta Michelangelo Antonioni ressoará novas possibilidades para a indexação fílmica e para Ciência da Informação. A composição de imagens feita pelo diretor suscita não apenas uma narrativa linear no tempo, mas também abre possibilidades de experimentação que escapam às estruturas linguísticas. Essa abertura à experimentação, e não à interpretação, nos interessa, visto que está em consonância com as proposições de Deluze. O filosofo francês não embarca na virada linguística. Para ele, a linguagem necessita sair dela mesma, necessita ser vista em sua pragmática, a qual articula conteúdo e expressão. A expressão nunca é uma representação, ela ocorre junto com o conteúdo, e não posteriormente; assim como, o conteúdo não simula a expressão. São processos agenciados e que efetuam as diferenciações no mundo. Tais diferenciações, sempre em devir, não aceitam categorias e descrições baseadas em grandes grupos, em grupos que permaneçam ao longo dos anos. Com Deleuze, lidamos com a experiência, com o efêmero, com o devir.

Lira (2016) relata a dificuldade em classificar ${ }^{3}$ os filmes em relação ao gênero, ficcional ou documentário, mesmo quando se articula as técnicas de filmagem, por exemplo, com o gênero do filme. As dificuldades estão na definição, na identidade dos gêneros e no julgo dos filmes. O mesmo ocorre nos estudos da linguagem documentária quando Smit (1988) questiona a transparência da imagem e a dificuldade em decifrar os limites entre o que é 
imagem e o que é real, entre o que é descrição e o que é interpretação. Tais problemas não importam mais, quando voltamos à atenção às sensações, no caso dos filmes de Antonioni, sensações ópticas.

\section{Filosofia de Deleuze e o cinema}

A filosofia de Deleuze funciona como uma grande máquina. Circuitos interligados veiculam fluxos entre diferentes corpos, materiais e imateriais, gerando uma ponte entre a virtualidade e a atualidade. Propor um conceito, pintar um quadro ou criar uma linguagem documentária menor é fazer trânsito nessa ponte das virtualidades. Nesse artigo, estamos lidando com conceitos filosóficos que pretendem ir ao virtual, retornar ao atual e manter a consistência da materialidade trazida. Tratamos da arte, especificamente do cinema, que traz do virtual ao atual um recorte plasmado da materialidade. Ainda, tratamos da Ciência da Informação que, em seu ir e vir ao virtual, desacelera as materialidades, conjugando-as e referencializando-as, visto que a ciência gera referências (não necessariamente as bibliográficas, mas aquelas axiomáticas, sem as quais seria impossível avançar em um raciocínio). Assim, buscamos entender como pensar com o cinema, na filosofia e na ciência?

O cinema clássico preocupa-se, principalmente, em contar histórias, sendo esta motivação da montagem e a submissão do tempo à imagem. Deleuze (2007) dirá que o cinema clássico promove o pensamento pelo "movimento", articulando uma continuidade da imagem ao pensamento, via montagem cinematográfica (como nos filmes de Eisenstein).

No cinema moderno, além dessa questão, torna-se preocupação da sétima arte o desenvolvimento de problemas. São renunciadas as figuras de linguagens e as montagens de oposição; assim como o plano sequencial substitui o corte cinematográfico. A relação cinema moderno e pensamento, agora, ocorre mediante as situações-problema, na medida em que há a libertação do tempo da imagem. Com isso, o cinema ganha complexidade, uma vez que evidência a própria exterioridade do cinema, na conjugação que desenvolve as situações óticas e sonoras puras. A exteriorização dos filmes nos contata e nos faz sentir e 
pensar (DELEUZE, 2007). Os filmes de Antonioni são modernos, constituídos por imagens-tempo.

\section{0 pós-estruturalismo e a Linguagem Documentária Menor}

Deleuze (2006) radicaliza o estruturalismo ao demonstrar os sete critérios em que este se reconhece. Tal radicalização permite chamarmos o estruturalismo deleuziano de pós-estruturalismo, mas com uma ressalva, pois sua proposta configura-se como uma prática viva e sem fixações, seja nos métodos ou no próprio corpo de conhecimento (WILLIAMS, 2013). São setes critérios:
a) o simbólico;
b) local / posição;
c) o diferencial e o singular;
d) o diferenciador e a diferenciação;
e) as séries;
f) casa vazia;
g) do sujeito à práxis.

No texto de Deleuze (2006), a cada critério, a complexidade vai aumentando, na medida em que o filósofo aprofunda nas relações que fundam o pós-estruturalismo. No primeiro critério, Deleuze revela uma dimensão que, por vezes, passa despercebida, é a dimensão do simbólico que, acrescida as outras duas, a do real e a do imaginário, constitui a tríade presente em qualquer estrutura. Para Deleuze (2006), o simbólico realiza duas funções: impede que haja limites entre o imaginário e o real e, também, movimenta um fluxo que veicula a dimensão virtual (caótica) da estrutura à realidade inteligível dos signos e das coisas. Portanto, é o simbólico quem nos permite acessar a estrutura. Os outros critérios orbitam essa dimensão (DELEUZE, 2006).

Os espaços/posições definem a estrutura pela composição da vizinhança entre esses mesmos lugares. Assim, "os lugares prevalecem sobre aquilo que os preenche", com isso, entendemos que "[...] os elementos simbólicos não tem designação extrínseca nem significação intrínseca, mas 
somente um sentido de posição." (DELEUZE, 2006, p. 226). É a combinação de elementos assemióticos que resulta no próprio sentido.

O pós-estruturalismo trabalha com as condições relacionais subjacentes às coisas e à linguagem, por isso se interessa mais pelo "[...] que está em jogo quando um conjunto de relações se distingue de outro." (WILliAMS, 2013, p. 90). Há uma emergência seletiva da estrutura, mas que não a define, visto que a estrutura é sempre um todo, um sistema completo de relações diferenciais. Essa emergência tem um percurso (o terceiro critério: os elementos assemióticos, ou relações diferenciais) da estrutura que adquire uma primeira consistência, tornando-se singularidades (sem identidade), que ocupam lugares e posições na estrutura.

Ao expor o quarto critério, Deleuze (2006, p. 231) retoma seu conceito de virtual, “[...] real sem ser atual, ideal sem ser abstrata [...]", afirmando que a estrutura é a virtualidade pensada a partir de um domínio que consiste em elementos, relações, valores de relações, singularidades especificadas pelo domínio. A atualização do virtual é um processo definido por coordenadas espaciais e temporais que selecionam elementos à emersão ao atual, um aqui-agora seletivo, lembrando que as partes não selecionadas da estrutura se atualizaram (ou se atualizarão) em outros "aqui-agora". Os elementos da estrutura e as singularidades organizam-se (avizinham-se) em séries (quinto critério). Há uma série das relações diferenciais que ressoa na série das singularidades ${ }^{4}$.

Assim, a estrutura é determinada pela constituição de uma segunda série que se mantém em relação com ela. Entre as duas séries, há apenas um ponto de convergência, algo da ordem do simbólico que se move entre ambas as séries: o "objeto $=\mathrm{x}$ " ou a casa vazia (sexto critério). A casa vazia, o objeto $=x$, não apresenta significação, mas um excesso de sentido, pois ele é o diferenciador da própria diferença. É com relação à movimentação da casa vazia que as séries são distribuídas e os lugares são ocupados, por isso é ela quem fundamenta a estrutura em um domínio qualquer. 
A casa vazia tem em seu vazio a condição de circular entre as séries e por em funcionamento a estrutura. Embora vazia e circulante, ela é sempre acompanhada por uma instância simbólica que é assujeitada a ela. Essa instância é o próprio sujeito que, no pós-estruturalismo, é compreendido sem uma identidade fixa e disperso na estrutura, na medida em que transita de um lugar a outro, acompanhando a casa vazia nesse nomadismo. É importante resistir a dois possíveis acidentes, a fim de manter a estrutura em atualização: devemos evitar que a instância deixe de seguir a casa vazia, assim como que a casa vazia perca sua mobilidade com seu preenchimento por uma identidade de um sujeito. Isto porque o real e o imaginário se constituem enquanto efeitos dos movimentos diferenciais na estrutura. Assim, falemos do conceito de inspiração deleuziana na Ciência da Informação, o conceito de linguagem documentária menor (LDM), proposto por Mostafa (2010; 2013). É esta uma forma de fugir das linguagens documentárias oficiais, maiores. Reúne passado e futuro, entra em devir, aceitando o paradoxal, tal como a epistemografia de Garcia Gutiérrez (2013). Com este conceito, é aceito o desacordo entre as palavras e as coisas e, já não nos interessa a fidelidade das representações, mas os afetos instigados pelos documentos pelos filmes. Ao cientista da informação é possível criar a partir dos afetos.

A LDM é uma maneira criativa de fuga da linguagem, como ferramenta cognitiva, que se dá mediante ao devir, e não mais pelo uso da inteligência e da razão. Esse é um passo importante para rompermos com os dogmatismos ainda incrustrados nas ciências, os quais delimitam os movimentos de pensamento. Para tanto, é necessário a abertura a uma experimentação completa da estrutura, ou em nosso caso, das sensações provocadas pelas imagens-tempo de Antonioni. Mostafa e Nova Cruz (2011) não só abordam a linguagem maior, dominante, e regida por palavras de ordem e atos de fala, mas também falam de uma linguagem em potência, dentro dessa linguagem maior. A linguagem adormecida pode ser produzida, na medida em que fazemos a linguagem maior variar. Assim, é possível minorar a linguagem por meio de variações, devires e 
criações: "[...] o que nos interessa, é um devir-menor da língua maior [...]" (MOSTAFA; NOVA CRUZ, 2011, p. 90).

A LDM estabelece-se em oposição à palavra de ordem, é uma revolta contra o poder estabelecido que se dá por meio de fugas desse mesmo poder compreendido como referencial e padrão. Essa fuga criativa não é histórica ou dialógica, mas é rizomática, resultante de um pensamento sensitivo, heterogêneo e múltiplo. Estabelece-se sem constantes ou estruturas rígidas, garantindo espaços de bifurcação. É horizontalizada e não apresenta categorias rígidas, o que permite o devir e a sua aproximação com a arte e a filosofia. Sendo assim, a LDM é uma alterativa ao tratamento documentário de filmes, sobretudo nos que promovem imagens-tempo.

\section{A imagem-tempo na trilogia de Antonioni}

A chamada trilogia da incomunicabilidade, formada pelos filmes $A$ aventura (L'AVVENTURA, 1960), A noite (LA NOTTE, 1961) e O eclipse (L’ECLISSE, 1962), parece fornecer elementos suficientes para problematizarmos a indexação das imagens no cinema moderno. Para essa trilogia, encontram-se várias análises (acadêmicas ou não) acompanhadas de vários referenciais teóricos.

Quatro textos acadêmicos surpreendem pelo quão recente são suas produções, considerando que estamos diante de uma trilogia do início dos anos 1960. Matos (2007), Chuang (2006), Ford (2003) e Airey (2014), só o primeiro em língua portuguesa, versando sobre dois filmes do cineasta: Crimes d'alma, de 1950, e O deserto vermelho, de 1964. Entretanto, Matos (2007) tece várias considerações de nosso interesse, uma vez que teoriza sobre a 'crônica visual' de Antonioni, sobre a qual já teremos que dar explicações ao leitor. Matos (2007) quer analisar os elementos visuais da obra de Antonioni, tendo em vista a inversão identificada entre imagem e texto, também chamada por ele de plástica e literatura. Não se corre atrás do texto para realizar ou contar a história, mas, ao contrário, ela é antes, construída pelas imagens. O autor faz uma crônica visual do cineasta pela ausência de ação nessas imagens e, também, ausência de 
aspectos psicológicos, uma vez que não conhecemos muito bem as personagens. Não há muitos diálogos, nem monólogos que nos façam aproximar do interior dos personagens. Daí, a crônica visual proposta pelo autor. Contam-se histórias, mas com pouquíssimo enredo, à moda de uma crônica e sem a banalidade do dia a dia, como explica Matos (2007). Até porque as personagens não se dedicam a atividades comuns ou corriqueiras; estão sempre fugindo, procurando algo ou alguém. "Mesmo entre quatro paredes, as figuras vão para o fundo ou para fora do quadro. Tudo parece mero pretexto para tornar o deslocamento uma atividade recorrente, pois nada desta animação se traduz em ação.” (MATOS, 2007, p. 112).

Assim, o objeto de análise, nos filmes de Antonioni, é a maneira como ele compõe as imagens, visto que seus filmes são pouco dramáticos e quase não nos identificamos com seus personagens, no sentido de amá-los ou rejeitá-los. A rigor, pouca coisa acontece nos filmes e, quando acontece, como é o caso do desaparecimento de Ana, no filme A aventura, logo, o foco desloca-se para uma procura fora da ilha, e não nos parece mais que estamos à procura daquele personagem. A tal ponto, que alguns críticos identificam o filme como o desaparecimento do desaparecimento. Alguns críticos identificam o apagamento dos personagens à profundidade de campo com que são filmados pelo cineasta.

Além disso, não há grande perturbação no tempo que é relativamente contínuo, face à ausência de enredo e intriga. As cenas e os espaços ensejam perspectivas longas, de tal maneira que os personagens podem entrar e sair da cena, estando ao fundo ou fora do quadro, mas não ao centro. Isso provoca um afastamento da própria história conosco; acompanhamos tudo, mas de longe. É por isso que os críticos chegam à conclusão de que os elementos visuais não são ilustrativos ou figurativos na obra de Antonioni, mas fazem parte da cena. Como comenta Matos (2007,), a composição plástica, não é adorno ou elucidação de um texto.

Construir uma imagem em perspectiva e uma narração, ou montagem elíptica, foram consideradas novidades cinematográficas, se comparadas ao cinema tradicional, isto é, o cinema clássico das décadas anteriores. Por isso, 
Antonioni foi considerado um dos fundadores do cinema moderno. Concordamos com Matos (2007) quando ele diz que, nos filmes de Antonioni, a temporalidade não absorve a narrativa como em outros cineastas, a exemplo de Resnais. No entanto, não se podem ignorar as novidades do tempo em sua filmografia. Se alguns autores defendem que os nexos em Antonioni são mais espaciais que temporais, e frente às posições da crônica visual que estamos comentando, em que esses nexos são mais plásticos que literários, o problema é entender em que medida esses nexos podem ser mais temporalizados dentro da periodização, proposta por Deleuze (2007), entre cinema clássico e cinema moderno. Justamente, essa é a tese da qual Matos (2007) quer se afastar, visto que ele entende que, já na primeira fase do cineasta, em seus primeiros filmes, havia certa independência entre imagens e enredo. "Os elementos visuais deixam de estar subordinados à estruturação do enredo, exigindo uma leitura independente, já nas primeiras obras.” (MATOS, 2007, p. 17). O autor adota, então, a contraposição entre plasticidade e literatura ou imagem e texto, preferencialmente, o cinema clássico e moderno.

Para Deleuze (2007), cinema clássico é o cinema da imagem-movimento, aquela em que o movimento subordina o tempo. Quando o movimento é dependente do tempo, estamos no regime da Imagem-Tempo. Para Deleuze (2007), a distinção entre esses dois tipos de imagens é a sua relação com o tempo. Assim, a imagem-movimento contém três tipos de imagem: imagenspercepção, imagens-ação e imagens-afecção.

Em uma cena de faroeste americano, por exemplo, a imagem-movimento especifica-se em: imagem-percepção (o mocinho vê o bandido); imagemafecção (o mocinho sente raiva); e imagem-ação (o mocinho enfrenta o bandido). O esgotamento dessas especificações se traduz na imagem-tempo que, por sua vez, especifica-se em cinco características: as situações são dispersivas e lacunares; a ligação entre as imagens é fraca; os personagens estão em perambulação; há uma tomada de consciência dos clichês; e finalmente, a denúncia de um complô que faz circular os clichês. Para Deleuze (2007), são as 
situações óticas e sonoras puras que não só desmontam o esquema sensóriomotor, bem como impedem a percepção de se prolongar em ação.

\subsection{A aventura}

A aventura (L'AVVENTURA, 1960) já faz parte da segunda fase de Antonioni, juntamente com A noite e $O$ eclipse. O segundo momento de Antonioni rompe com a estrutura romanesca e teatral do neorrealismo, apresentando um novo cinema especificamente audiovisual (ROCHA, $2006{ }^{5}$ apud VIEIRA, 2015). Mota (2007) comenta, em nota de rodapé, que, pela primeira vez no filme $A$ aventura, Antonioni introduz ruídos externos à diegese ${ }^{6}$, como o som do vento, das ondas e dos passos. A fase final seria representada, segundo Glauber Rocha, por Blow up; depois daquele beijo, em que o cineasta extrapola a Itália em um tom mais anti-imperialista (ROCHA, 2006 ${ }^{7}$ apud VIEIRA,2015).

A aventura conta a história de um grupo de amigos ricos em um passeio em alto mar e na visita a uma ilha vulcânica do sul da Itália. Um personagem que pensávamos ser central, Ana, desaparece na ilha, e o grupo se divide na busca dentro e fora da ínsula. O tempo é implacável, e tanto os personagens como os espectadores sentem sua presença, pela impossibilidade de caminhar com facilidade na ilha vulcânica; pela imensidão da paisagem; pelo isolamento em que se constitui toda ilha; pela espera; e por não poder fazer nada. Tanto os personagens quanto os espectadores, sofrem a presença de um tempo implacável que nos transforma de alguma maneira. Esse tempo se move lentamente, esvaziando as pessoas e suas capacidades de agir diante de uma temporalidade sublime e devastadora a cada momento que passa. O tempo nos invade, e, atravessados pelo tempo, acabamos por flexibilizar nossas crenças e desacreditar de nossas certezas. Perdemos o desejo de controle e, quiçá, sentimo-nos meio perdidos. 


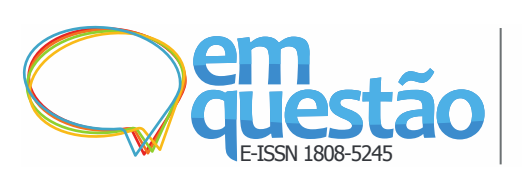

Eros e a Ciência da Informação

Solange Puntel Mostafa, Igor Soares Amorim, Deise Maria Antonio Sabbag

Figura 1 - A aventura cena 1

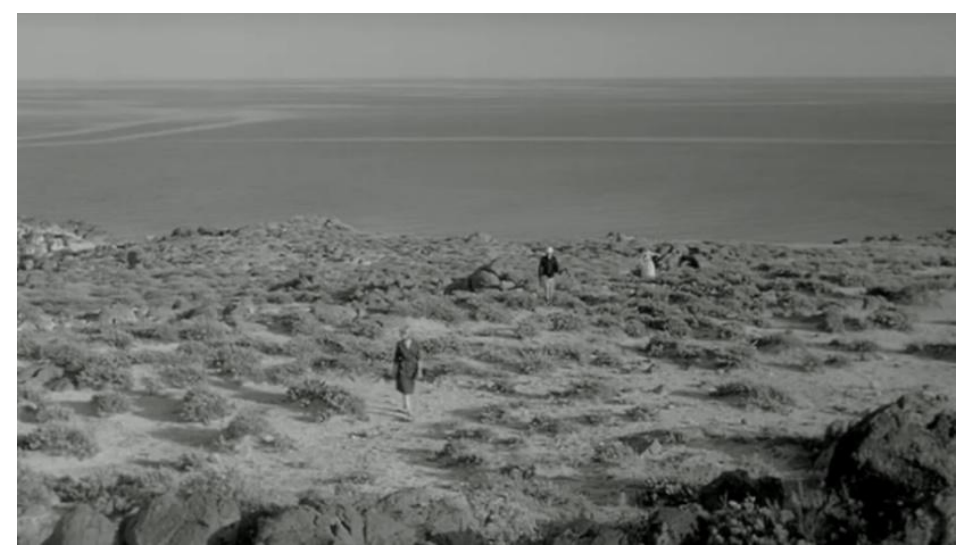

Fonte: Ford (2003).

Em $A$ aventura, apresenta-se o que, talvez, para Antonioni, fale mais alto: a compaixão pela fraqueza e miséria humana, já que Sandro, o exnamorado de Ana e, agora, amante de Cláudia, não satisfeito, abandonará Cláudia em um quarto de hotel, para encontrar-se com outra mulher que viu no mesmo hotel. A cena final mostra Sandro desolado, em lágrimas diante da imensidão do mar e de Cláudia que, com compaixão, toca-lhe o ombro.

Figura 2 - A aventura cena 2

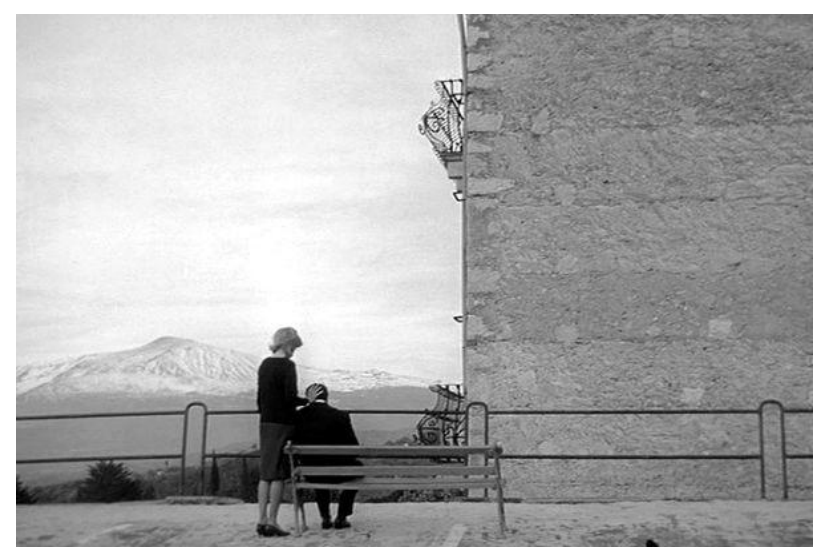

Fonte: Lima (2012).

Neste cinema, constituído por imagens-tempo, os personagens tornam-se videntes e não agem mais. "Por mais que se mexa, corra, agite, a situação em que está extravasa, de todos os lados, suas capacidades motoras, e lhe faz ver e 
ouvir o que não é mais passível, em princípio de uma resposta ou ação." (DELEUZE, 2007, p. 11). Assim, o drama tradicional torna-se um drama ótico, no dizer do filósofo. Deleuze diz que "[...] a situação puramente ótica e sonora desperta uma função de vidência, a um só tempo fantasma e constatação, crítica e compaixão..." (DELEUZE, 2007, p. 30).

A questão do olhar está muito presente nos três filmes da incomunicabilidade. Contudo, ainda em A aventura, o casal parece estar sendo perseguido pelo olhar da desaparecida o tempo todo. E até mesmo os espectadores sentem-se assombrados pelo olhar da mulher cujo paradeiro nunca saberão. É esse olhar que explica, segundo Deleuze (2007, p. 18), “[...] a incoordenação de seus movimentos objetivos, quando ele foge, alegando ir procura-la [...]".

Uma beleza e uma frustração envolvem o filme $A$ aventura: a desconfortável presença do tempo que força o pensamento a pensar o impensável e a não menos vastidão do espaço que faz desaparecer o rosto dos personagens, deixando-nos outra vez sem emoções com as quais nos identificar. Contudo, é aí mesmo que Antonioni quer chegar. Segundo Deleuze (2007), o cineasta Antonioni está mais perto de Nietzsche que de Marx, porque quer fazer uma verdadeira crítica da moral e não apenas da moral capitalista.

\subsection{A noite}

Em A noite (LA NOTTE, 1961), o que mais chama atenção é justamente a ausência de fatos ou ocorrências marcantes, pois qualquer outra coisa é mais importante do que se passou. A sinopse aponta um casal, Giovanni Pontano (Marcello Mastroianni) e Lidia (Jeanne Moreau), que estão casados há 10 anos. O relacionamento entre eles está desgastado, especialmente em relação à comunicação.

Aqui, também sentimos a presença do tempo. Lídia busca o passado para comunicar-se com seu marido. O pensamento e o despertar espiritual não precisam ser expressos com palavras ou diálogos nos filmes de Antonioni. Os 
personagens recorrem ao passado para dar sentido a sua existência ou a dos outros. O tempo não aparece na tela, mas tem o poder de despertar os personagens. Como o tempo não pode ser representado diretamente, as imagenstempo recaem sobre situações óticas, sonoras e táteis que permitem ao espectador estar consciente do tempo como tema central.

Em A noite, a câmera capta a linguagem poética dos personagens e, junto com as situações óticas e sonoras, faz as pessoas sentirem a mesma compaixão altruísta já notada no filme $A$ aventura. Vemos os 'videntes' invadirem a tela, pois os personagens de $A$ noite são também espectadores e, nesse sentido, registram mais do que reagem.

O casal vai pela manhã a um vernissage de Giovanni, que é escritor. Após algum tempo, Lídia se enfastia e sai do local a passear sem rumo. À noite, eles vão a uma festa em uma mansão milionária. A cronologia manhã, tarde e noite suscita um comentário interessante de Matos (2007, p. 11):

[...] muito mais do que organizar os conflitos pessoais, a cronologia estabelece uma continuidade plástica da luz. A claridade da manhã... as evidraças dos prédios refletem ainda mais a forte claridade do sol da manhã, destacando a dureza da cidade moderna [...].

O autor continua relacionando as velhas construções da periferia com a luz do crepúsculo, e a casa noturna com a sombra da noite. Consoante à tese de Matos de deslocar a imagem-tempo da centralidade da sua crônica visual, o autor conclui que a "[...] estrutura temporal mais do que impor ordem nos acontecimentos reitera o forte formalismo das imagens.” (MATOS, 2007, p. 11). Não discordamos do formalismo das imagens, mas também não desprezamos os signos temporais apresentados no filme.

No passeio vespertino de Lídia, a câmera repousa em sua mão, quando ela entra em algum prédio destruído da periferia e toca na madeira apodrecida da porta; o envelhecimento do prédio e do seu casamento, ou o tempo que passou. Antonioni focaliza um relógio quebrado nos escombros do prédio, como se olhar para o relógio pudesse reviver um passado diacrônico que o relógio registra sincronicamente na tela. 
Figura 3 - A noite cena 1

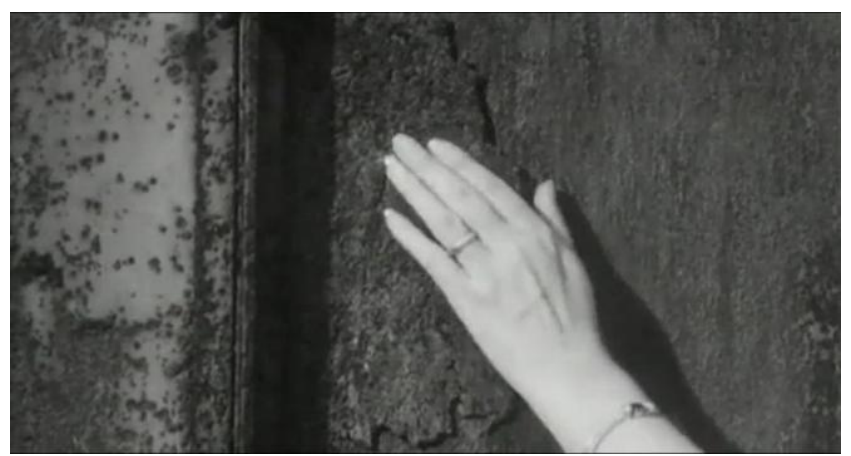

Fonte: La notte (1961).

$\mathrm{O}$ toque na pintura da porta, o choro da criança que aparece e rapidamente desaparece entre os escombros e o relógio quebrado são imagens desconexas e aproximadas com cortes irracionais que desorientam o espectador. Segundo Deleuze (2007), a imagem-tempo não associa ações, mas as imagens associam-se como agenciamento em relações incomensuráveis entre elas.

Quando Giovani termina a sua sessão de vernissage e vai ao encontro de Lídia, ela comenta que, naquele mesmo parque antigo, os jovens estão agora se divertindo de jogar foguetes. Na periferia, ela percebe o quão moderna cidade de Milão se tornou. O barulho das ruas é ensurdecedor, e esse é outro aspecto das situações óticas e sonoras de que fala Deleuze, visto que este som faz parte da imagem que agora é audiovisual. Diz Deleuze (1990, p. 35):

Ao mesmo tempo que o olho acede a uma função de vidência, os elementos da imagem, não só visuais, mas sonoros, entram em relações internas que fazem com que a imagem inteira deva ser'lida' não menos que vista, legível tanto quanto visível.

Em A noite, as conversas não parecem ter muito sentido, e o barulho da rua forma o soundtrack do filme. Antonioni continua filmando Jeanne Moreau após a cena terminada. Em entrevistas, ele afirma a crença de que no intervalo entre personagem e pessoa pode haver novas possibilidades.

Assim como Antonioni usou intervalos irracionais, como linguagem poética entre as imagens, ele fez poesia explícita no final do filme, com a leitura 
da carta que um dia, no passado, ele teria escrito sobre o seu amor por Lídia. Essa carta-passado despertou vida nele, na saída da festa milionária, por meio da consciência do tempo.

\subsection{0 eclipse}

Se Deleuze tem razão ao aproximar Antonioni de Nietzsche (DELEUZE, 1990), talvez, estejamos tratando, neste filme, do eclipse da espécie humana, ou pelo menos do homem moderno, pois como nota Glauber Rocha “[...] o que é O eclipse senão o documento deste mundo morto, onde a máquina capitalista esmagou o amor?” (ROCHA, $2006^{8}$ apud VIEIRA, 2015, p. 4). Em O eclipse (L'ECLISSE, 1962), Vitoria separa-se de seu noivo Ricardo, um intelectual de meia-idade e depois encontra o jovem corretor da bolsa de valores, Piero. Entre dois relacionamentos, Vitoria é uma pessoa alienada e insatisfeita, vagando pelas ruas da Roma dos anos 1960.

A sequência inicial de $O$ eclipse conecta-se com a última cena, onde são filmados espaços vazios da cidade e, sobre esses espaços vazios, há muito o que se comentar.

Figura 4 - Eclipse cena 1

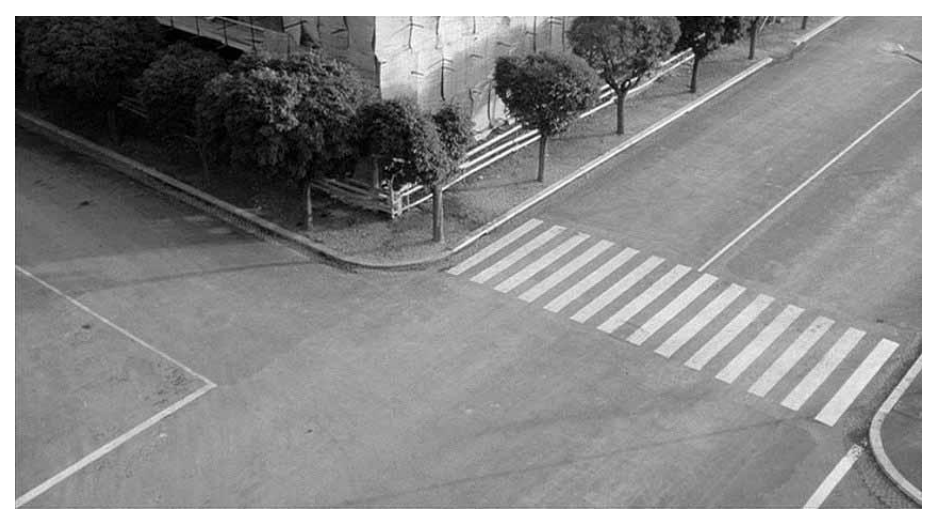

Fonte: Rodrigues, 2012.

No espaço in-doors do apartamento, encontramos o casal em gestos dissonantes: ele catatônico, sentado em sua mesa de trabalho com o olhar 
absolutamente parado em um ponto da sala, e Vitoria andando de um lado para o outro como um animal confinado.

A noção de imagem do tempo fornece uma postura interpretativa sobre o modo como a alienação motiva a mudança. Ao exibir a crise de alienação pósguerra, Antonioni apresenta o que Deleuze denomina o "cinema do vidente", substituindo o "drama tradicional" por um novo tipo de "drama ótico", em que o eu alienado vagueia em torno de espaços, incapaz de absorver os espaços em que se encontra. No entanto, encontrando-se neste estado, ela é impulsionada para o pensamento que, por sua vez, a leva a uma nova experiência sensorial. Com a crise pós-guerra da alienação, vem a descoberta do novo. Assim, o espaço não existe como na imagem-movimento direcionada à ação, ele está lá para ser explorado. A percepção agora não é mais estendida à ação, mas colocada em contato com o pensamento (DELEUZE, 2007). Assim, veremos Vitoria com uma expressão morosa em seu rosto, enquanto ela se move para o primeiro plano, pegando um objeto na mesa diante dela. Antonioni apresenta um cinzeiro e uma escultura na mesma mesa, é quando a mão de Vitoria se move e começa a reorganizar os objetos, colocando-os dentro e fora do quadro. Esta reorganização de objetos torna-se uma atividade interessante para uma Vitoria indiferente.

Nesta sequência de abertura, ela é uma "vidente" em sua própria casa. O familiar espaço do apartamento torna-se, para Vitoria, um lugar de isolamento. A princípio, ela não reconhece o espaço doméstico e, portanto, o explora. Itens domésticos comuns - uma moldura, um cinzeiro e uma escultura - neste caso, provocam o pensamento. A ação que ela realiza, isto é, a colocação de objetos, é aparentemente sem sentido e não a leva logicamente a uma nova situação. Sentado inerte no canto da sala, Ricardo olha enquanto Vitoria explora o espaço. A sequência dura quase cinco minutos sem diálogo. Silenciosamente, Vitoria e Ricardo examinam um ao outro, bem como o seu ambiente.

Como uma "vidente", operando por meio da pura situação óptica, Vitoria vê um tipo diferente de imagem. Quando ela mergulha sua mão no quadro e reorganiza as formas geométricas, Vitoria mostra que a "estética" não é fixa, 
mas aberta à escolha e à determinação humana. Como Deleuze (2013) aponta, quando o esquema sensório-motor emperra um tipo diferente de imagem pode aparecer. É possível que a imagem sem metáfora, a que Vitoria teve acesso no início do filme, tenha trazido imagens e pensamentos fora das imagens clichês. São pequenas porções de imagem-tempo, pois a personagem feminina parece tão perdida quanto Ricardo, embora seja ela que tem coragem de romper e sair do apartamento. É quando começa sua perambulação. A câmera acompanha por um bom tempo as andanças de Vitoria nas ruas de Roma.

O que está eclipsado são os próprios sentimentos humanos, mas, para Deleuze (2013), o que Antonioni está mostrando não é a incomunicabilidade ou a solidão humana em suas formas costumeiras, mas o imenso cansaço do corpo: “[...] o corpo nunca está no presente, ele contém o antes e o depois, o cansaço, a espera. O cansaço, a espera, e até mesmo o desespero são atitudes do corpo. Ninguém foi mais longe nesta direção do que Antonioni [...]” (DELEUZE, 2013, p. 227). Para Deleuze (2013), não se trata de alienação no sentido negativo, mas aquela que faz ver novos mundos possíveis.

Deleuze (2007) afirma que em Antonioni, desde o filme "A aventura, a grande busca de Antonioni é o plano vazio, o plano desabitado." (DELEUZE, 2007, p. 18). Ao final de $O$ eclipse, todos os planos percorridos pelo casal são revistos e corrigidos pelo vazio. De fato, a cena final de $O$ eclipse soma oito minutos de espaços vazios, sem a presença humana: as ruas, os bueiros, o vento na árvore, a noite que cai, enfim, o mundo sem a presença dos homens.

E uma entrevista de 1961, Antonioni fala da doença de Eros ou da separação do cérebro com todos os conhecimentos e os avanços da técnica e da ciência e um corpo pesado, neurótico, refém de sentimentos antigos. É como se houvesse um desequilíbrio, entre uma ciência que avança sem cessar e uma moral rígida que conservamos por desleixo ou por preguiça. 
Figura 5 - Eclipse cena 2

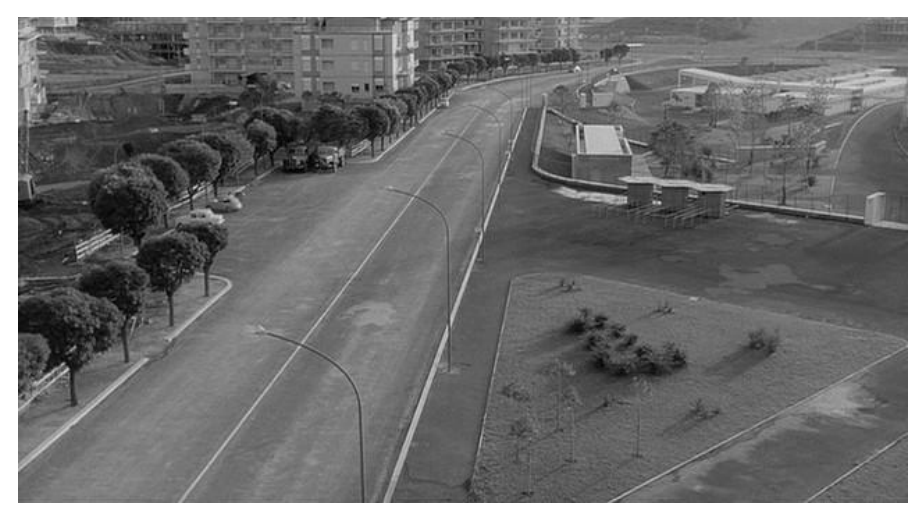

Fonte: L'Eclisse (1962).

\section{Descrição fílmica na Ciência da Informação: a trilogia de Antonioni}

Temos trazido a filosofia para as análises fotográficas e fílmicas, porque acreditamos que o deslizamento de planos entre ciência, filosofia e arte pode beneficiar essas três formas de pensamento. Cremos, também, que a ciência da informação pode explorar um lado mais nomádico das suas práticas informacionais. Sob o feixe luminoso dos três filmes, problematizamos suas indexações.

A International Federation of Film Archives (FIAF), consolidou-se na década de 1930, com o intuito de preservar e de intercambiar (informações, filmes e materiais correlatos) do cinema em âmbito mundial. A federação lançou uma norma para descrição dos filmes, em 1985. Desde então, a norma tem sido atualizada e traduzida em diversos idiomas. O Glossary of filmographic terms (FÉDÉRATION INTERNATIONALE DES ARCHIVES DU FILM, 2012) indica cinco áreas de descrição de filmes, dentre as quais nos interessa a descrição de conteúdo:
a) identificação básica;
b) ficha técnica e elenco;
c) distribuição e exibição;
d) forma e conteúdo;
e) propriedades. 


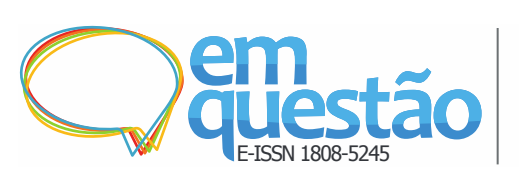

Sobre a descrição de conteúdo, a norma destaca três seções: gênero, sinopse e temas/assunto. No temas/assunto, os “[...] termos descritores do conteúdo de um filme especificando o seu período, assuntos, locações, eventos, etnia dos personagens, etc. Não confundir com Gênero." (FÉDÉRATION INTERNATIONALE DES ARCHIVES DU FILM, 2012, p. 59, tradução nossa).

Focando na descrição de temas, assuntos, a norma requer a descrição de período, assuntos, locações, eventos, etnia dos personagens. Tais índices orientam a indexação, porém, não há uma especificação do que significa uma locação, ou de um evento no conteúdo de um filme. Ainda, destacamos que não existe nem na seção de conteúdo, nem em outra área um campo em que a descrição, a partir da leitura dos afetos do filme, possa ser descrito.

As metodologias de descrição fílmica na Ciência da Informação têm-se desenvolvido segundo várias metodologias mais ou menos completas. Cordeiro e Amâncio (2005), por exemplo, apresentam um modelo para análise e representação de filmes de ficção e para aplicação em unidades de informação como cinematecas, videotecas, bibliotecas e arquivos. Tal modelo integra aspectos descritivos e de representação do conteúdo do filme. Assim, na descrição temos o título do filme, a existência de diálogos / dublagem / legendas / intertítulos e a ficha técnica resumida.

Quanto ao conteúdo, delineiam-se facetas como: gênero; registro temporal da trama; gancho temporal; referência histórica; temas representados; estrutura narrativa; natureza da representação; sequências relevantes; aproximações temáticas da(s) sequência(s) escolhida(s); sinopse; instrumentos documentais; complementações; informações extrafílmicas; e observações.

Nas locadoras, vemos os filmes separados por cineastas quando reúnem várias obras, tornando-se assim famosos. Além disso, mais comumente, os filmes são reunidos por gêneros, tipo westerns/faroestes, crime, gay, drama, de época, comédias, etc. Contudo, esses gêneros nada nos dizem sobre os diferentes tipos de imagens ou suas características. Por mais útil que sejam estas categorias de gênero, Deleuze (2013) as descartou em favor de uma nova taxonomia, para 
responder às ligações intrínsecas entre as imagens. A invenção temática dos filmes apontando gênero aposta no análogo linguístico, como se o cinema fosse uma língua; e supõe também a separação entre pensamento e imagem, mente e matéria. Já o sistema de classificação de Deleuze (2013) insiste precisamente na formula ontológica, na qual há uma quádrupla identidade entre imagem, matéria, movimento e percepção.

A trilogia da incomunicabilidade está contemplada na Internet Movie Database (IMDb), provavelmente a mais completa base de dados de filmes, músicas, programas e comerciais televisivos e jogos de computador. Herr e colaboradores (2007) afirmam que é a base de dados fílmica mais popular e completa disponibilizada via internet. No IMDb a indexação é feita pelos usuários que sugerem os termos, afim de descreverem os conteúdos dos filmes. A base apresenta os termos de acordo com sua relevância. O filme $A$ aventura (L'AVVENTURA, 1960) apresentou 26 termos; o filme A noite (LA NOTTE, 1961) apresentou 50; e $O$ eclipse (L'ECLISSE, 1962) apresentou 153. Trazemos aqui os dez termos mais relevantes de cada filme:

Quadro 1 - termos indexados

\begin{tabular}{|c|c|}
\hline \multicolumn{2}{|c|}{ Termos indexadores atribuídos por usuários na base IMDb } \\
\hline A aventura, 1960 & $\begin{array}{l}\text { proposta de casamento; amigos; ilha; pesquisa; } \\
\text { desaparecimento; Sicília; iate; Itália; escrito pelo } \\
\text { diretor; o personagem diz que te amo }{ }^{9}\end{array}$ \\
\hline A noite, 1961 & $\begin{array}{l}\text { festa; escritor; casamento; relacionamento marido } \\
\text { esposa; socialite; infidelidade; hospital; ponto de } \\
\text { vista do personagem; referência a gabriele } \\
\text { d'annunzio; referência a Ernest Hemingway }{ }^{10}\end{array}$ \\
\hline O eclipse, 1962 & $\begin{array}{l}\text { amor; bolsa de valores; tradutor; mercado de ações; } \\
\text { Roma; esgueirando-se atrás de alguém; Verona; } \\
\text { barril de água; fim ambíguo; injúria racial }{ }^{11}\end{array}$ \\
\hline
\end{tabular}

Fonte: Elaborado pelos autores com base na IMDb (Internet Movie Database, c2017).

Com base no documento da FIAF (FÉDÉRATION INTERNATIONALE DES ARCHIVES DU FILM, 2012), nas proposições de Cordeiro e Amâncio (2005) e termos utilizados para descrever a trilogia da incomunicabilidade no 
$\mathrm{IMDb}$, notamos que não existem, ainda, subsídios para um tratamento documental adequado da imagem-tempo na Ciência da Informação. A imagemtempo é um conceito de Deleuze (2013), filósofo que se opõe ao cogito ergu sum de Descartes, retomando a crítica nietzschiana e destacando que, antes do pensamento descrito na máxima de Descartes, há uma sensação que possibilita o pensamento. A filosofia de Deleuze (2013) é aberta as sensações advindas do virtual, da estrutura, dos filmes. Imagem-tempo são sensações que nos impacta nos filmes modernos.

\section{Conclusão}

Lidar com sensações e afetos é proposição de uma Ciência da Informação menor, nômade, preocupada não mais com os universalismos, as essências transcendentes dos objetos e dos assuntos e as representações. Para tanto, é necessário corroborarmos a LDM que, talvez, nos permita explorar melhor esse universo menor da informação. As imagens-tempo de Antonioni não constroem uma narrativa linear e lógica, não operam pelos eixos sintagmático e paradigmático, não delimitam personagens-tipo. No entanto, nos permitem experimentações de afetos via as composições de imagens óticas e sonoras puras que mantém as lacunas, as perambulações e o esfacelamento dos clichês.

Em $A$ aventura, surgem as sensações em relação à força de um tempo que não passa, não cessa, que prende os personagens, cada um em sua ilha e que cria uma expectativa de rompimento deste isolamento que não se confirma.

No filme A noite, o tempo é ainda mais estruturante das imagens óticas, sonoras e táteis. Ao evidenciar ao espectador a sua condição, torna o casamento de Lídia inerte e incolor, caracterizando este relacionamento angustiante. As cenas de perambulação revelam a não-ação das personagens que apenas capturam as imagens, como os espectadores.

Em $O$ eclipse, há um aprofundamento da crise do sujeito na modernidade, isolado e desencaixado de seus espaços urbanos, os quais ele não reconhece e, por isso, leva o sujeito a pensar por suas sensações, constantemente. Essa 
constante angustia presente no estranhamento cansa, assim como cansa o vazio nas cenas finais.

Como indexar tais imagens? Objetivamos a fuga dos macro e micropoderes, por meio de creditar o valor informacional, não em uma réplica sintética de informação, mas na criação de um ente que dialogue com a comunidade, abrindo perspectivas e bifurcações, rompendo com o óbvio e municiando a própria comunidade em seus processos de diferenciação. Analisamos neste artigo a trilogia de Antonioni, mas algumas especificidades da imagem-tempo perpassam centenas de cineastas em várias especificações e precisam ser levadas em conta na hora de indexar, tais como: as situações óticas e sonoras puras, o reconhecimento atento, os cortes irracionais, a narração cristalina e os cristais do tempo, bem como as potências do falso que são os termos adequados às imagens-tempo.

No caso da trilogia, ganham relevância termos como espaços esvaziados, perambulação e vidência e doença de Eros. A LDM contribui, assim, com a indexação com termos que dizem os próprios afetos. Assim, ao invés de perguntar como indexar, preferimos perguntar quais os afetos suscitados pela trilogia de Antonioni?

\section{Referências}

AIREY, M. The 'Seer' in Michelangelo Antonioni’s L'eclisse (1962). 2014.

CAMPOS, A. T. A indexação. Revista de Biblioteconomia de Brasília, Brasília, v. 15, n. 1, p. 69-72, 1987.

CHAUMIER, J. Indexação: conceito, etapas e instrumentos. Revista Brasileira de Biblioteconomia e Documentação, São Paulo, v. 21, n. 1/2, p. 63-79, jan./jun. 1988.

CHUANG, A. In search of lost time: La Notte and the time-image. 2006. Thesis (Master of Arts) - Faculty of the Graduate School of Vanderbilt University, Nasville, 2006. 
CORDEIRO, R. I. N.; AMÂNCIO, T. Análise e representação de filmes em unidades de informação. Ciência da Informação, Brasília, v. 34, n. 1, p. 89-94, jan./abr. 2005.

DELEUZE, G. Cinema 1: a imagem-tempo. São Paulo: Brasiliense, 2013.

DELEUZE, G. Cinema 2: a imagem-tempo. São Paulo: Brasiliense, 2007.

DELEUZE, G. Em que se pode reconhecer o estruturalismo? In: DELEUZE, G. A ilha deserta. São Paulo: Iluminuras, 2006. p. 221-247.

DELEUZE, G; GUATARRI, F. Mil platôs. São Paulo: Editora 34, 2010.

FÉDÉRATION INTERNATIONALE DES ARCHIVES DU FILM. Glossary of filmographic terms. Belgium, 2012.

FORD, Hamish. Antonioni's Lávventura and Deleuze's Time-image. Senses of Cinema, Melbourne, n. 28, oct. 2003.

GARCÍA GUTIÉRREZ, A. Estructura linguística de la documentación: teoría y método. Murcua: Universidad de Murcia, 1990.

GARDIN, Jean-Claude. Document analysis and linguistic theory. Journal of Documentation, London, v. 29, n. 2, p. 137-168, 1973.

HERR, Bruce W. et al. Movies and actors: mapping the Internet Movie Database. In: INTERNATIONAL CONFERENCE ON INFORMATION VISUALIZATION, 11., 2007, Zurich. Proceedings... Zurich, 2007. p. 465-469.

HESÍODO. Teogonia: a origem dos deuses. 3. ed. São Paulo: Iluminuras. 1995. INTERNET MOVIE DATABASE. c2017.

L'AVVENTURA. Direção: Michelangelo Antonioni. Roteiro: Michelangelo Antonioni, Elio Bartolini, Tonino Guerra. 1960. 143min, mono, p\&b.

L'ECLISSE. Direção: Michelangelo Antonioni. Roteiro: Michelangelo Antonioni, Tonino Guerra, Elio Bartolini, Ottiero Ottieri. 1962. 126 min, mono, $\mathrm{p} \& \mathrm{~b}$.

LA NOTTE. Direção: Michelangelo Antonioni. Roteiro: Michelangelo Antonioni, Tonino Guerra. 1961. 122 min, mono, p\&b.

LARA, Marilda Lopes Ginez. O processo de construção da informação documentária e o processo de conhecimento. Perspectivas em ciência da informação, Belo Horizonte, v. 7, n. 2, jul./dez. 2002.

LIMA, Juliana. A aventura da comunicação. Cinéfilos, São Paulo, set. 2012. 
LIRA, B. S. Ética e estética: o papel da indexação na recepção de um filme. Aniki: Revista Portuguesa da Imagem em Movimento, Braga, v. 3, n. 1, p. 5-20, jan./jul. 2016.

MATOS, Y. A. V. F. A crônica visual de Michelangelo Antonioni. 2007. Tese (Programa de Pós-Graduação em Filosofia) - Universidade de São Paulo, São Paulo, 2007.

MOSTAFA, S. P. Epistemologia ou Filosofia da ciência da informação. Informação \& Sociedade, João Pessoa, v. 20, n. 3, maio/ago. 2010.

MOSTAFA, S. P. Filosofia da diferença e a ciência da informação. Rio de Janeiro: E-papers, 2013.

MOSTAFA, S. P.; NOVA CRUZ, D. V. Por uma linguagem documentária menor. In: BOCCATO, V. R. C.; GRACIOSO, L. S. (Org.). Estudos de linguagem em ciência da informação. Campinas: Alinea, 2011. p. 69-96.

NIETZSCHE, F. Genealogia da moral: uma polêmica. São Paulo: Companhia de Bolso, 2008.

ORTEGA, C. D.; LARA, M. L. G. A noção de documento: de Otlet aos dias de hoje. DataGramaZero: Revista de Ciência da Informação, Rio de Janeiro, v. 11, n. 2, abr. 2010.

RODRIGUES, C. T. Antonioni e o niilismo contemporâneo. Horizontes afins, [S.1.], out. 2012.

ROCKENBACH, F. Conceitos narrativos: Diegese. 2014.

SMIT, J. W. A representação da imagem. Informare, Rio de janeiro, v. 2, n. 2, p. 28-36, jul./dez. 1996.

VIEIRA, C. A aventura, a noite e o eclipse: Antonioni e o cinema moderno.

Revista Digital de Psicanálise e Cultura da Escola Brasileira de Psicanálise, Belo Horizonte, n. 3, set. 2015.

WILLIAMS, J. Pós-estruturalismo. 2. ed. Petrópolis: Vozes, 2013.

\section{Eros and Information Science}

Abstract: Analysis on the different plans among Philosophy, Information
Science and Arts through the trilogy of incommunicability based on the movies
directed by Michelangelo Antonioni, with the aim of outlining and
experimenting ways of indexing outside the frames of Information Science 
structuralism. We use the philosophical concept of Minor Documentary Language to present new terms for the indexation of these movies, based on the philosophy of Gilles Deleuze, specifying the Information Science structuralism.

Keywords: Trilogy. Incommunicability. Time-image. Gilles Deleuze. Michelangelo Antonioni.

Recebido: 06/04/2017

Aceito: $26 / 07 / 2017$

${ }^{1}$ Ao invés do termo "análise documentária", optamos pela designação, "linguagem documentária", que pode referir-se tanto a prática, como aos instrumentos que visam controlar os vocabulários utilizados num sistema de recuperação da informação (GARCIA GUTIÉRREZ, 1990).

2 Tais categorias foram inspiradas nas facetas desenvolvidas pelo Classification Research Group, importante grupo inglês no desenvolvimento de vocabulários controlados durante os anos 1950 e 1960.

${ }^{3}$ No texto, Lira (2016) utiliza o termo "indexar".

${ }^{4}$ A dimensão do real e do imaginário são efeitos das relações e valores constituídos entre essas duas séries.

${ }^{5}$ ROCHA, G. O século do cinema. São Paulo: Cosac Naif, 2006. Apud Vieira (2015).

${ }^{6}$ Diegese é um conceito fundamental de ser compreendido para qualquer análise referente a uma narrativa cinematográfica. Como muitos dos conceitos utilizados para análise crítica ou roteiro, vem da literatura. É um conceito de narratologia, que diz respeito à dimensão ficcional de uma narrativa. De forma simplificada, representa a realidade da narrativa que se desenrola à nossa frente, diferente da realidade do mundo que nos cerca. É o mundo ficcional, a vida fictícia vendida pelo roteiro e pronta para ser "comprada" pelo espectador. Quando falamos em DIEGESE podemos falar do narrador, do tempo e do espaço. O tempo diegético e o espaço diegético são, assim, o tempo e o espaço que decorrem ou existem dentro da trama, com suas particularidades, limites e coerências determinadas pelo autor (ROCHENBACH, 2014)

${ }^{7}$ ROCHA, G. O século do cinema. São Paulo: Cosac Naif, 2006. Apud Vieira (2015).

${ }^{8}$ ROCHA, G. O século do cinema. São Paulo: Cosac Naif, 2006. Apud Vieira (2015).

${ }^{9}$ No original: marriage proposal; friend; island; search; disappearance; sicily; yacht; italy; written by director; character says i love you

${ }^{10}$ No original: party; writer; marriage; husband wife relationship; socialite; infidelity; hospital; character's point of view camera shot; reference to gabriele d'annunzio; reference to ernest hemingway

${ }^{11}$ No original: love; stock exchange; translator; stock market; roma; sneaking up behind someone; verona; water barrel; ambiguous ending; racial slur. 